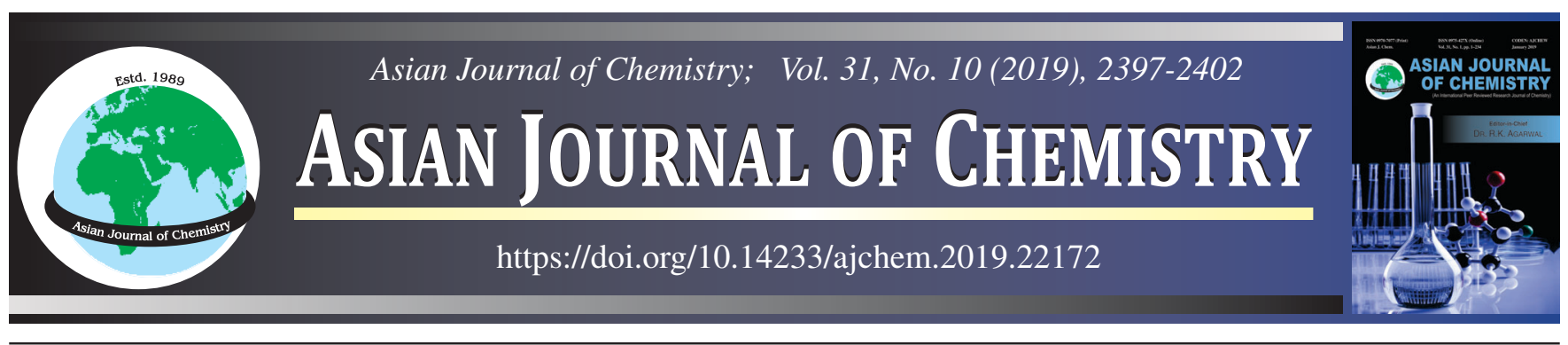

\title{
Biosynthesis, Anti-TB Activity and Degradation of \\ Dyes by Silver Nanoparticles using Fruits Peels
}

\author{
Harpreet KaUR* and AbHinav Sharma
}

Department of Chemistry, Lovely Professional University, Phagwara-144411, India

*Corresponding author: E-mail: harpreet2.kaur@lpu.co.in

Received: 1 May 2019;

Accepted: 18 July 2019;

Published online: 30 August 2019;

AJC-19559

\begin{abstract}
In the present work, waste materials such as pomegranate and orange peels were taken to synthesize nanoparticles by biological method. The method did not involve the use of toxic reducing and capping agents. It uses only the environmentally benign biomolecules for reduction of $\mathrm{AgNO}_{3}$ and subsequent stabilization of silver nanoparticles. The size of pomegranate and orange silver nanoparticles varied from 8-25 nm with nearly spherical morphology as analyzed by XRD and TEM studies. The synthesized nanoparticles were studied for their dye degrading property. Different dyes such as crystal violet, methylene blue, malachite green and Congo red were taken for the study. The results indicated the presence of two diverse mechanism of dye removal. Crystal violet, methylene blue, malachite green was removed by adsorption onto both the nanoparticles, whereas Congo red was reduced by $\mathrm{NaBH}_{4}$ in the presence of catalytic pomegranate silver nanoparticles. Moreover, pomegranate silver nanoparticles have exhibited potent antitubercular activity with MIC value of $6.25 \mu \mathrm{g} /$ $\mathrm{mL}$ and orange silver nanoparticles are moderately active with MIC value of $25 \mu \mathrm{g} / \mathrm{mL}$. It could be concluded that the pomegranate silver nanoparticles would a promising candidate for drug development and catalysis.
\end{abstract}

Keywords: Silver nanoparticles, Photodegradation, Dyes, Anti-TB activity.

L

\section{INTRODUCTION}

Nanoparticles are the particles of very small size ranging from $1 \mathrm{~nm}$ to $100 \mathrm{~nm}$ and have distinct properties which make them beneficial in almost all the fields like medicine, biological products, cosmetics, aerospace, military, etc. Size of nanoparticles plays a vital role. This is because of all the electrical, optical, catalytic, magnetic properties vary according to the variation in their size [1]. Nanoparticles can be natural like from volcanic eruptions, ocean spray, etc. They can be incidental like combustion products, frying, mining, etc. They can be engineered like quantum dots, fullerenes, etc. [2]. There are newly discovered silver nanoparticles which can deliver a large amount of drug in the body and this delivering can be controlled [3]. These metal nanoparticles are quite useful in treating tumors and cancers and based on polysilsesquioxane particles which are silicon resin [3]. The metal nanoparticles are similar to biomolecules because of same size range from 1 to $100 \mathrm{~nm}$ and thus quite useful in bioimaging and biosensing [4]. Metal nanoparticles can modify with different types of moieties like cationic, anionic, neutral, etc. because of their small size and high surface area. Thus, have enormous applications in biological sciences [1]. Nanoparticles of noble metals are very compatible, have good catalytic activity and conductivity [5].

For the synthesis of silver nanoparticles various physical and chemical methods have been employed but these methods involve the use of toxic compounds and generate hazardous by products $[6,7]$. The use of biological entities, namely, microorganisms and plants, has been explored for the synthesis of silver nanoparticles and has been found to be a clean, nontoxic and environmentally acceptable method [8]. Plant mediated synthesis of silver nanoparticles have various advantages such as cost effectiveness, non-toxicity and ecofriendly products [9]. Extracts of many plants have been successfully used for the synthesis of silver nanoparticles [10-12]. Silver nanoparticles release silver ion after entering aqueous environment $[13,14]$, which reduces the stability of silver nanoparticles, but these biogenic nanoparticles are quite stable. Congo red is an azo dye and very toxic and non-biodegradable. This dye is a byproduct of dying industries and it misbalances the aquatic

This is an open access journal, and articles are distributed under the terms of the Attribution 4.0 International (CC BY 4.0) License. This license lets others distribute, remix, tweak, and build upon your work, even commercially, as long as they credit the author for the original creation. You must give appropriate credit, provide a link to the license, and indicate if changes were made. 
environment by polluting water [15]. Mycobacterium tuberculosis (TB) is a serious public health concern as it is a leading infectious cause of death. However, a number of new chemical compounds having significant antitubercular activity have been recently discovered, but no new drug has entered the market from the last 55 years [16]. The known drawbacks of current existing drugs with the emergence of MDR strains and the increasing occurrence of death due to TB have arisen interest in the discovery and development of new anti-tubercular drugs with novel mode of action. So, there is an essential need to discover and develop the new anti-TB drugs [17].

The present study was undertaken to biosynthesize silver nanoparticles and evaluate the potential of waste plant materials for dye removal and to evaluate its potency against Mycobacterium tuberculosis. The objective of the study is to convert waste materials into a useful material. Furthermore, in order to investigate the medicinal importance of nanoparticles, they were tested against Mycobacterium tuberculosis.

\section{EXPERIMENTAL}

The waste materials viz. orange peels and pomegranate peels were procured for the local fruit market. The chemicals and solvents silver nitrate, ethanol, methanol, malachite green, methylene blue, Congo red, crystal violet dye, sodium borohydride, ethanol, hexane were procured Sigma-Aldrich, USA.

Preparation of plant extract: Orange and pomegranate peels were washed shade dried. The dried material was extracted with ethanol using Soxhlet apparatus. The extract was than distilled by rota-evaporation to get the solid mass.

Preparation of silver nanoparticles: The synthesis of silver nanoparticles was done from the orange and pomegranate extracts. Two stock solutions were made, one of plant extract and another of silver nitrate. Plant extract $(1 \mathrm{~g})$ was taken in a $100 \mathrm{~mL}$ volumetric flask and mixed with $100 \mathrm{~mL}$ of deionized water, then $\mathrm{AgNO}_{3}(0.1 \mathrm{mM})$ was made in 1000 $\mathrm{mL}$ of deionized water. Different ratios of plant extract to silver nitrate solution were used for the optimization of silver nanoparticles preparation of a particular plant and the best ratio was selected with the help of UV-Vis Spectroscopy.

UV-visible analysis: The progress of reaction was monitored by UV-Vis spectral analysis done with UV-1800 double beam (SHIMADZU, Tokyo, Japan) and the spectra were recorded from 200 to $800 \mathrm{~nm}$. The reduction of pure $\mathrm{Ag}^{+}$ions was confirmed by the presence of characteristic peaks of surface plasmon resonance.

TEM analysis: Transmission electron microscopy (TEM) technique was used to observe the morphology of silver nanoparticles. Transmission Electron Microscope, Hitachi (H-7500) $120 \mathrm{kV}$ equipped with CCD Camera instrument having the resolution of $0.36 \mathrm{~nm}$ (point to point) with $40-120 \mathrm{kV}$ operating voltage and with magnification up to 6 lakh times in high resolution mode was used for the present study. TEM grids were prepared by placing $5 \mu \mathrm{L}$ of AgNP solutions on carbon-coated copper grids and thereafter dried under lamp.

XRD analysis: The powdered AgNP were drop-coated onto a glass substrate and the XRD measurements were carried out using a Panalytical's X'Pert Pro X-ray diffractometer with the working conditions: $\mathrm{CuK}_{\alpha}$ Ni-filtered radiation; $40 \mathrm{kV}, 30 \mathrm{~mA}$; divergence slit $0.47^{\circ}$. The instrument was made up of vertical theta-theta goniometer having range of $0-160^{\circ} 2 \theta$. The radiation was $\mathrm{CuK} \alpha$ and nickel metal was used for beta-filter. Sample was coated uniformly on glass side (size $3.5 \mathrm{~cm} \times 2.5 \mathrm{~cm}$ and thickness $0.2 \mathrm{~cm}$ ) for taking out the diffractogram.

FTIR analysis: The presence of functional groups in the phytoconstituents of fruit peels extracts and their involvement in the synthesis of AgNPs were determined by FT-IR studies. The FT-IR analysis was carried out by a SHIMADZU FT-IR 8400 S (Tokyo, Japan) operating in the range between 4000 to $400 \mathrm{~cm}^{-1}$.

Anti-TB activity using alamar blue dye: The antimycobacterial activity of compounds was studied using micro plate alamar blue assay (MABA) against $M$. tuberculosis [18]. The 96 wells plate was taken for the study, $100 \mu \mathrm{L}$ of Middle brook $7 \mathrm{H} 9$ broth and serial dilution of compounds were done. The range of final drug concentrations were 100 to $0.2 \mu \mathrm{g} / \mathrm{mL}$. Plates were sealed and incubated at $37^{\circ} \mathrm{C}$ for five days. After five days, $25 \mu \mathrm{L}$ of freshly prepared 1:1 mixture of alamar blue reagent and $10 \%$ Tween 80 was added to the plate and incubation was done for another $24 \mathrm{~h}$. A blue colour in the well indicated no bacterial growth and pink colour was marked as cell growth. The MIC was defined as lowest concentration of the compound that prevented the colour change from blue to pink.

Reducing property of silver nanoparticles: Four organic dyes viz. malachite green, Congo red, methylene blue and crystal violet dye are degraded using silver nanoparticles. Three stock solutions are made. The stock solution I contains $10^{-3} \mathrm{M}$ aqueous solution of each organic dye separately. The stock solution II contains aqueous solution of metal nanoparticles. The stock solution III contains $10^{-3} \mathrm{M}$ aqueous solution of sodium borohydride [19]. The first conical flask contains aqueous solution of dye. The second conical flask contains dye and silver nanoparticles. The third flask contains dye, silver nanoparticles and aqueous solution of sodium borohydride. The fourth flask is a control as it contains dye and sodium borohydride. These flasks are continuously stirred and UV spectra is taken after a fixed interval till the discolouration of dye takes place.

\section{RESULTS AND DISCUSSION}

The progress of reaction was visualized by colour change of solution from yellow to brown and it was further monitored using UV-visible spectroscopy. There was a characteristic peak at $420 \mathrm{~nm}$ which corresponded to the surface plasmon resonance for silver nanoparticles [20]. From the UV spectra of orange peel AgNPs (Fig. 1), it became evident that the absorbance was maximum at optimum time of $6 \mathrm{~h}$ and the rate of reduction of silver was fastest in 8:2 $\left(\mathrm{AgNO}_{3}\right.$ : extract).

Similarly, the optimization of conditions of silver nanoparticles synthesis from the pomegranate peel extract was done with the help of UV-visible spectroscopy. It was concluded from the spectra that best ratio for reduction of silver was 7:3 and time required for reaction completion was $4 \mathrm{~h}$ as shown in Fig. 1.

The characterization of nanoparticles was done on the basis of IR spectra, overlay of IR spectra of both extracts and their silver nanoparticles (Fig. 2) showed absorption bands at 3474 and $1734 \mathrm{~cm}^{-1}$, which corresponded to the presence of 

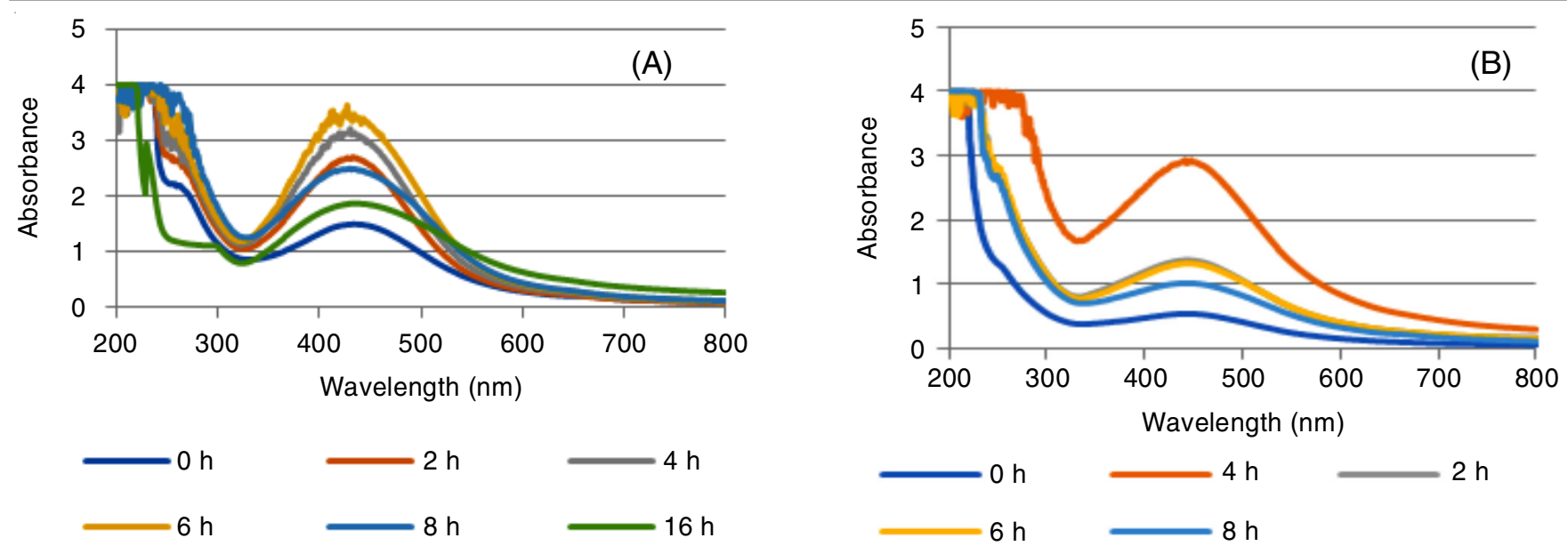

Fig. 1. Variation in absorbance of (A) orange peels silver nanoparticles (B) pomegranate nanoparticles with reaction time
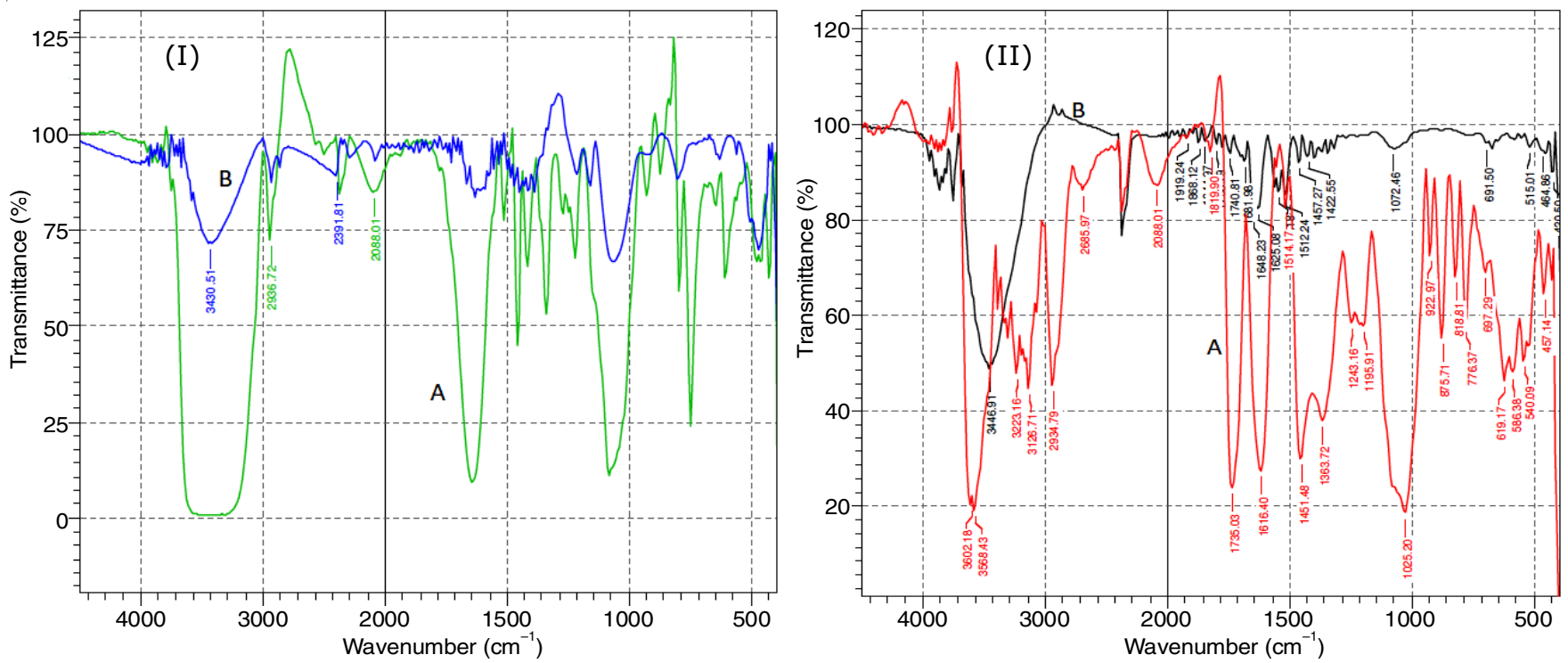

Fig. 2. Overlay of IR spectra of (I) (A: orange peel extract and B: orange extract silver nanoparticles); (II) (A: pomegranate peel extract and $\mathrm{B}$ : pomegranate extract silver nitrate nanoparticles)

$\mathrm{OH}$ and $\mathrm{C}=\mathrm{O}$ stretching $(\mathrm{COOH})$, respectively. Further, bands at 1616 and $1435 \mathrm{~cm}^{-1}$ were assigned to $\mathrm{C}=\mathrm{C}$ stretching in case of aromatic compounds present in the pomegranate extract. The presence of such peaks indicated the presence of phytochemicals adhering to the surface of silver nanoparticles, and these phytoconstituents led to the stabilization of nanoparticles [21]. Similar observations were obtained for pomegranate nanoparticles and it was concluded that similar groups were capping the silver nanoparticles.

The X-ray diffraction patterns of synthesized AgNPs from pomegranate peels as depicted in Fig. 3 revealed the presence of diffraction peaks at $32.859^{\circ}, 34.974^{\circ}, 49.321^{\circ}, 53.720^{\circ}$, $56.469^{\circ}, 61.795^{\circ}$ and $78.618^{\circ}$ that corresponded to fcc geometry characteristic of AgNPs [22]. The particle size was calculated by Scherrer's method, it was found to be $15.9 \mathrm{~nm}$. The X-ray diffractogram (Fig. 4) displayed similar diffraction pattern for orange peels and showed the presence of peaks at $32.1778^{\circ}$, $38.0706^{\circ}$ and $54.9319^{\circ}$ with average particle size of $19.1 \mathrm{~nm}$.

The surface morphology of orange peel silver nanoparticles and pomegranate peel nanoparticles was found out by TEM analysis as shown in Fig. 5. The shape of silver nanoparticles

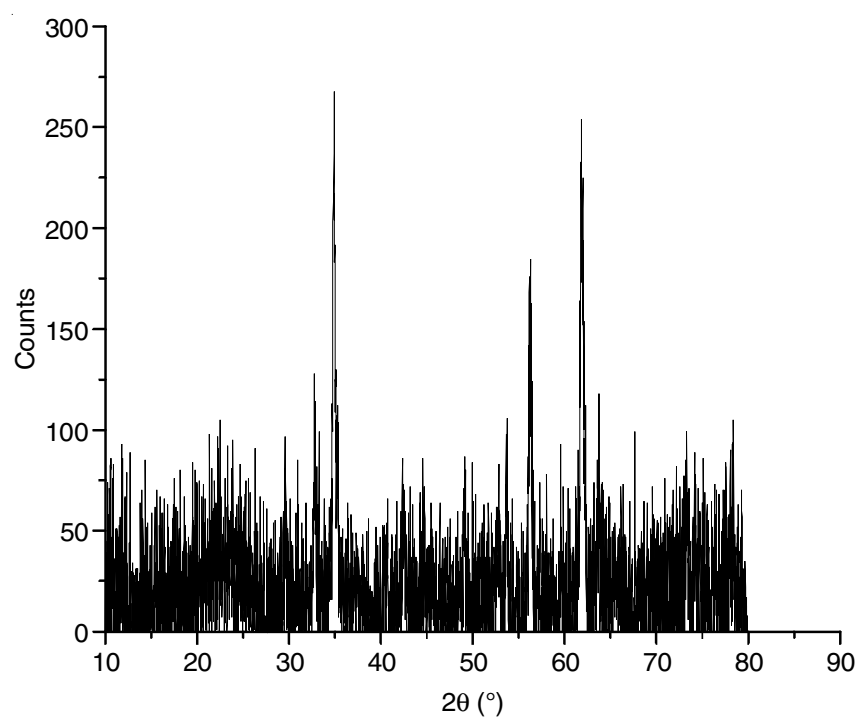

Fig. 3. XRD spectrum of pomegranate peels AgNP

was nearly spherical with smooth surfaces. A closer view of particle showed the capping by phytochemicals on its surface. 


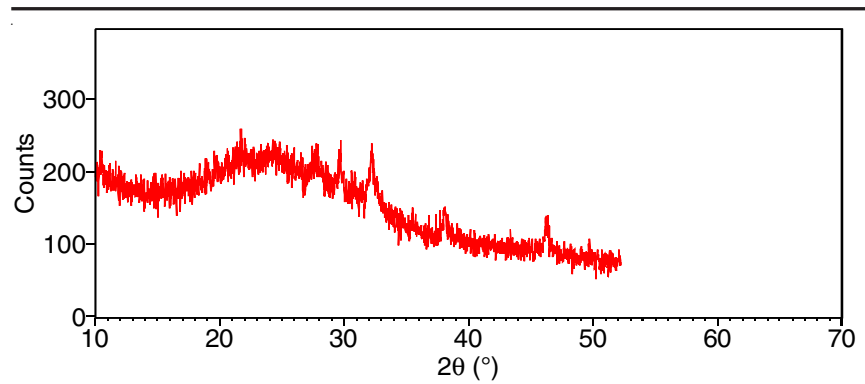

Fig. 4. XRD spectrum of orange peels AgNP

Dye degrading activity of nanoparticles: The silver nano-particles from both the fruits waste was used to degrade four dyes. The reaction of dye with both the silver nanoparticles was visualized with the help of UV-visible spectrometer and the change was recorded in form of spectra as shown in Figs. 6 and 7. Pomegranate peels AgNPs was found to degrade crystal violet, Congo red and malachite green, methylene blue, on the other hand orange AgNP could degrade three dyes except Congo red. All the dyes except, Congo red adsorbed on the surface of nanoparticles and hence removed from the solution. That was easily concluded from the reduction in the absorbance values of dye solutions with increase in time of exposure of dye with silver nanoparticles (Fig. 7). The absorbance at $\lambda_{\max }$ was decreased with addition of small amounts of nanoparticles within an hour, no additional peak was observed in any of the

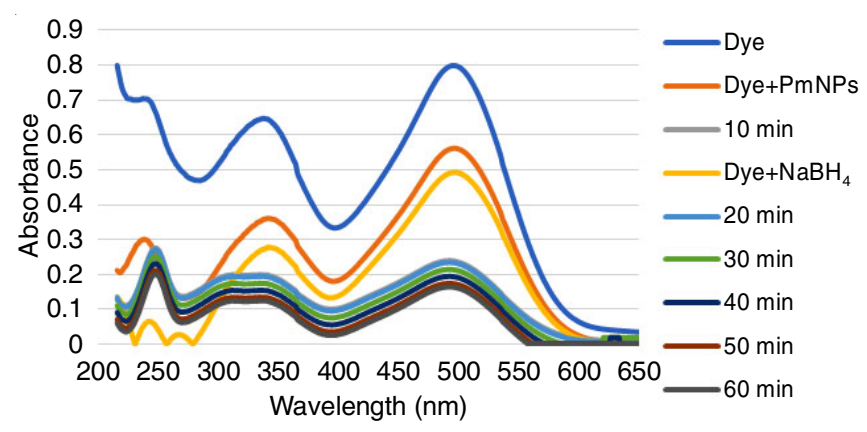

Fig. 6. Catalytic activity of Ag NP of Punica granatum spectra, indicating that these dyes are degraded by simply adsorption of coloring molecules onto the surface of nanoparticles.

The absorption spectra of Congo red was quite different from that of other dyes. Congo red due to its complex structure was not adsorbed rather it was reduced by $\mathrm{NaBH}_{4}$ in the presence of pomegranate silver nanoparticles as catalyst. The silver nanoparticles $(15 \mathrm{mg})$ were used to catalyze reduction of the dye with $\mathrm{NaBH}_{4}$. From Fig. 6, it could be visualized that there was a shift in $\lambda_{\max }$ from 500 to $250 \mathrm{~nm}$. In the initial dye solution with less time of contact of nanoparticles with dye, there was an absorption peak at about $500 \mathrm{~nm}$ due to presence of $\mathrm{N}=\mathrm{N}$ chromophoric group. With the increase in time of contact of dye with silver nanoparticle, the chromophoric group was reduced by $\mathrm{NaBH}_{4}$ in the presence of dye. Hence, the peak at $500 \mathrm{~nm}$ disappeared and a new peak at a wavelength of 250 $\mathrm{nm}$ (due to aromatic $\mathrm{NH}_{2}$ group) appeared. It could be proposed that $\mathrm{NaBH}_{4}$ was adsorbed on the silver nanoparticle surface thereby increasing the surface area for reduction of $\mathrm{N}=\mathrm{N}$ bond into $\mathrm{NH}_{2}$ groups and making the dye solution colourless. The proposed mechanism could be depicted diagrammatically in Fig. 8.

Orange peels silver nanoparticles were not able to remove Congo red dye. The reason for such observation might be due to the presence of phytochemical capping the nanoparticles, did not support the adsorption of $\mathrm{NaBH}_{4}$. From the above discussion, it became clear that dyes were degraded by two diverse mechanisms. The mechanism of adsorption and catalytic activity for removal of dyes have been proposed by earlier workers as well [23].

Antitubercular activity of nanoparticles: Silver nanoparticles produced from fruit peels were further investigated for their biological activity and tested against Mycobacterium tuberculi. The pomegranate nanoparticles were found to be quite active with MIC value of $6.25 \mu \mathrm{g} / \mathrm{mL}$ and orange nanoparticles were active with MIC value of $25 \mu \mathrm{g} / \mathrm{mL}$ as depicted in Table-1. It could be inferred that pomegranate peels silver nanoparticles are more potent than orange peels silver nano-
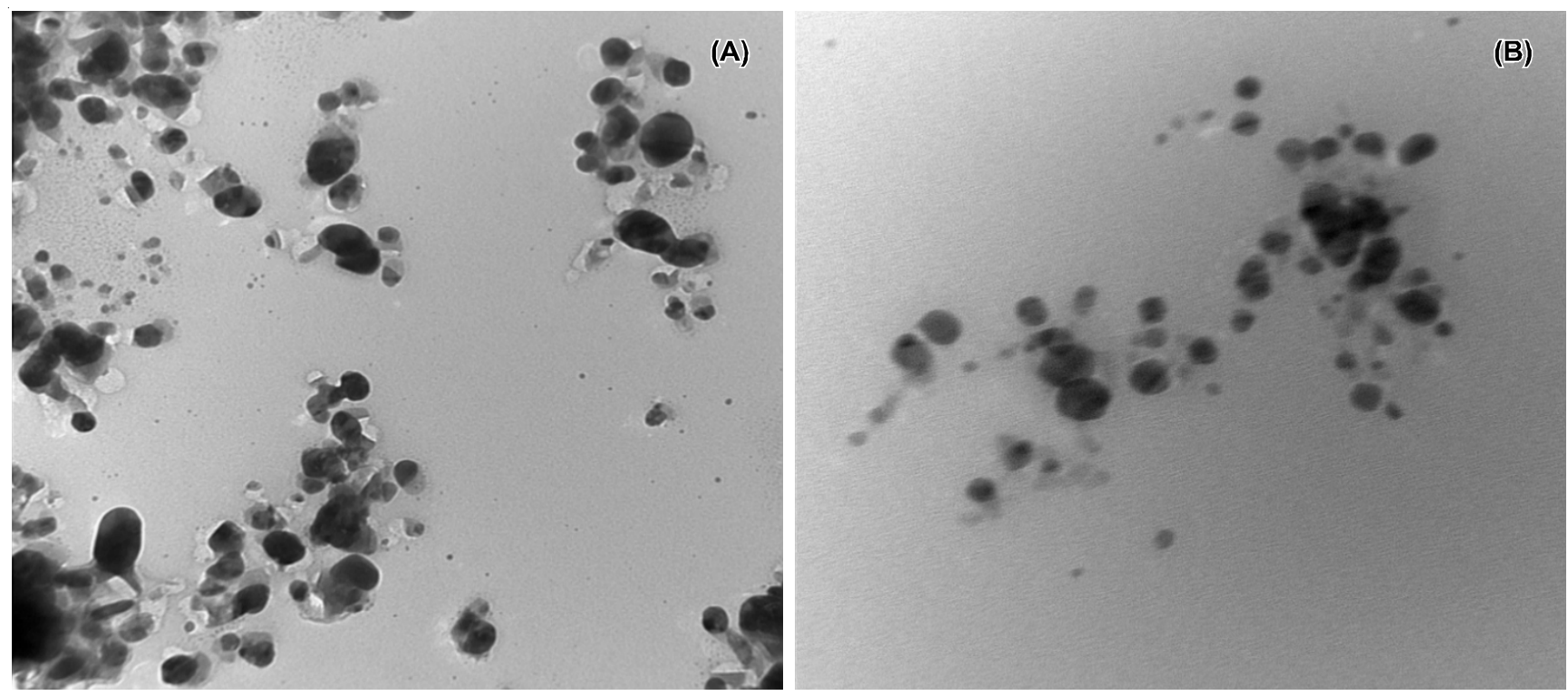

Fig. 5. TEM images of (A) pomegranate nanoparticles and (B) orange nanoparticles 

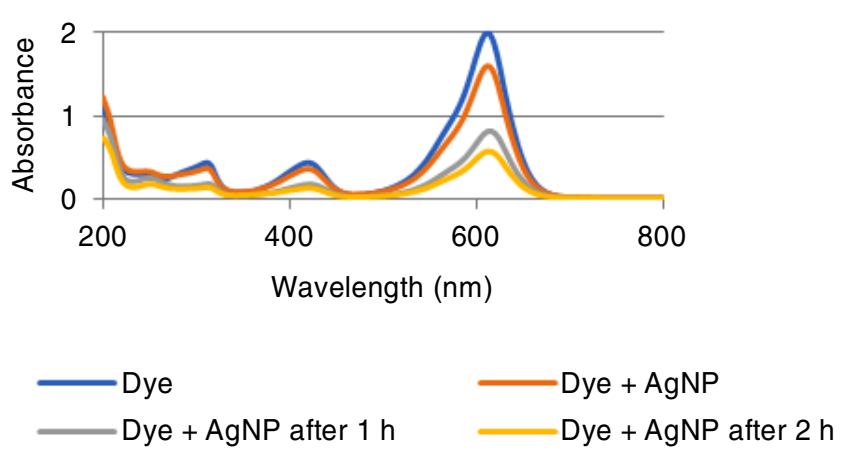

Removal of malachite green with $10 \mathrm{mg} \mathrm{AgNP}$ (orange peels)
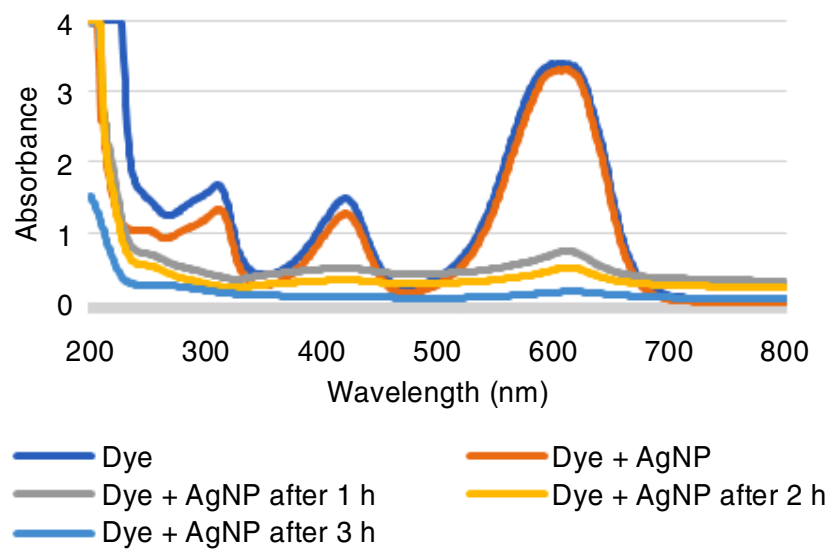

Removal of malachite green with $20 \mathrm{mg}$ AgNP (pomegranate peels)
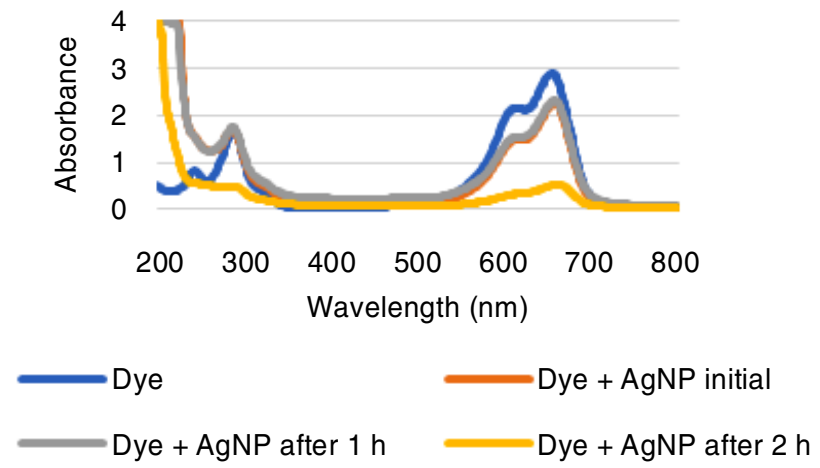

Removal of methylene blue with $20 \mathrm{mg}$ AgNP (orange peels)

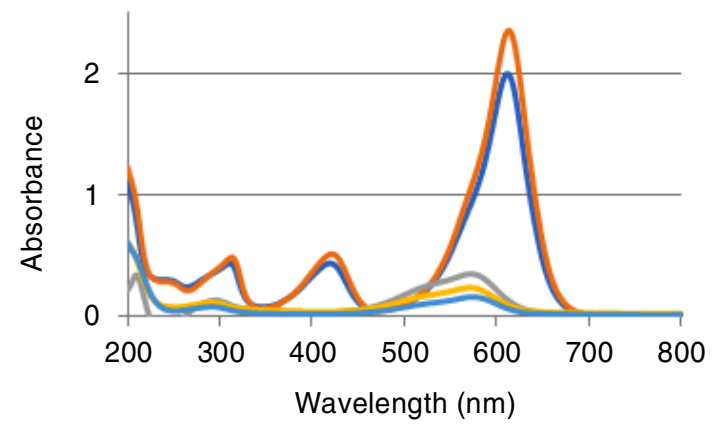

Dye after $1 \mathrm{~h}$
Dye + AgNP initial
Dye + AgNP (2 h)

Fig. 7. Adsorption activity of nanoparticles for dyes

\begin{tabular}{|c|c|c|c|c|c|c|c|c|}
\hline \multicolumn{9}{|c|}{$\begin{array}{c}\text { TABLE-1 } \\
\text { ANTITUBERCULAR ACTIVITY OF FRUIT PEELS AgNP }\end{array}$} \\
\hline Sample & $100 \mu \mathrm{g} / \mathrm{mL}$ & $50 \mu \mathrm{g} / \mathrm{mL}$ & $25 \mu \mathrm{g} / \mathrm{mL}$ & $12.5 \mu \mathrm{g} / \mathrm{mL}$ & $6.25 \mu \mathrm{g} / \mathrm{mL}$ & $3.12 \mu \mathrm{g} / \mathrm{mL}$ & $1.6 \mu \mathrm{g} / \mathrm{mL}$ & $0.8 \mu \mathrm{g} / \mathrm{mL}$ \\
\hline Pomegranate peels AgNP & Sensitive & Sensitive & Sensitive & Sensitive & Sensitive & Resistant & Resistant & Resistant \\
\hline
\end{tabular}<smiles>CS(=O)(=O)Oc1cc(N=Nc2ccc(-c3ccc(N)c(N=Nc4ccc(-c5ccc(N=Nc6cc(OS(N)(=O)=O)c7ccccc7c6N)cc5)cc4)c3)cc2)c(N)c2ccccc12</smiles>

Fig. 8. Proposed scheme of catalytic activity for reduction of Congo red by AgNP particles. Further study could be undertaken to ascertain the mechanism of its activity.

\section{Conclusion}

It could be concluded from the present study that the fruit wastes like peels of orange and pomegranate could be utilized to biosynthesize silver nanoparticles. The synthetic method is quite simple as no requirement of any type of stabilizing agent and thus poses no threat to living beings as well as to environment. It is also inferred from the study that pomegranate peels silver nanoparticles exhibited good catalytic activity for removal of Congo red dye from water and both the silver nanoparticles are working as good adsorbent for dye removal. So, silver nanoparticles could be further studied for dye removal from contaminated water from textile industries. Furthermore, pomegranate silver nanoparticles as compared to orange silver nanoparticles are quite potent against $\mathrm{Myco}$ bacterium tuberculi and can be considered as a good drug candidate. 


\section{CONFLICT OF INTEREST}

The authors declare that there is no conflict of interests regarding the publication of this article.

\section{REFERENCES}

1. A.K. Khan, R. Rashid, G. Murtaza and A. Zahra, Trop. J. Pharm. Res., 13, 1169 (2014); https://doi.org/10.4314/tjpr.v13i7.23.

2. M.L. Etheridge, S.A. Campbell, A.G. Erdman, C.L. Haynes, S.M. Wolf and J. McCullough, Nanomedicine, 9, 1 (2013); https://doi.org/10.1016/j.nano.2012.05.013.

3. P.A. Underhill, P. Shen, A.A. Lin, L. Jin, G. Passarino, W.H. Yang, E. Kauffman, B. Bonné-Tamir, J. Bertranpetit, P. Francalacci, M. Ibrahim, T. Jenkins, J.R. Kidd, S.Q. Mehdi, M.T. Seielstad, R.S. Wells, A. Piazza, R.W. Davis, M.W. Feldman, L.L. Cavalli-Sforza and P.J. Oefner, Nat. Genet., 26, 358 (2000); https://doi.org/10.1038/81685.

4. P. Mohanpuria, N.K. Rana and S.K. Yadav, J. Nanopart. Res., 10, 507 (2008); https://doi.org/10.1007/s11051-007-9275-X.

5. A.V. Zayats and V. Sandoghdar, J. Microsc., 202, 94 (2001); https://doi.org/10.1046/j.1365-2818.2001.00810.x.

6. V.P. Manjamadha and K. Muthukumar, Bioprocess Biosyst. Eng., 39, 401 (2016); https://doi.org/10.1007/s00449-015-1523-3.

7. E.C. Njagi, H. Huang, L. Stafford, H. Genuino, H.M. Galindo, J.B. Collins, G.E. Hoag and S.L. Suib, Langmuir, 27, 264 (2011); https://doi.org/10.1021/la103190n.

8. S. Ahmed, Saifullah, M. Ahmad, B.L. Swami and S. Ikram, J. Radiat. Res. Appl. Sci., 9, 1 (2006); https://doi.org/10.1016/j.jrras.2015.06.006.

9. D. Nath and P. Banerjee, Environ. Toxicol. Pharmacol., 36, 997 (2013); https://doi.org/10.1016/j.etap.2013.09.002.

10. M. Dubey, S. Bhadauria and B.S. Kushwah, Dig. J. Nanomater Biostruct., 4, 537 (2009).
11. A. Bankar, B. Joshi, A.R. Kumar and S. Zinjarde, Colloids Surf. B Biointerfaces, 80, 45 (2010); https://doi.org/10.1016/j.colsurfb.2010.05.029.

12. J. Baharara, F. Namvar, T. Ramezani, N. Hosseini and R. Mohamad, Molecules, 19, 4624 (2014); https://doi.org/10.3390/molecules 19044624.

13. W. Zhang, Y. Yao, N. Sullivan and Y. Chen, Environ. Sci. Technol., 45, 4422 (2011); https://doi.org/10.1021/es104205a.

14. J. Liu and R.H. Hurt, Environ. Sci. Technol., 44, 2169 (2010); https://doi.org/10.1021/es9035557.

15. H. Kolya, P. Maiti, A. Pandey and T. Tripathy, J. Anal. Sci. Technol., 6, 33 (2015); https://doi.org/10.1186/s40543-015-0074-1.

16. M.R. Gajula and Y.V.R. Reddy, Eur. J. Chem., 5, 374 (2014); https://doi.org/10.5155/eurjchem.5.2.374-379.1027.

17. S. Dwarampudi, S.R. Dannana, G.S. Avupati and V.S.M. Bendi, Eur. J. Chem., 5, 570 (2014); https://doi.org/10.5155/eurjchem.5.4.570-576.1098.

18. M.C.S. Lourenço, M.V.N. de Souza, A.C. Pinheiro, M. de L. Ferreira, R.S.B. Gonçalves, T.C.M. Nogueira and M.A. Peralta, Arkivoc, 181 (2007); https://doi.org/10.3998/ark.5550190.0008.f18.

19. T.N.J.I. Edison, Y.R. Lee and M.G. Sethuraman, Spectrochim. Acta A: Mol. Biomol. Spectrosc., 161, 122 (2016); https://doi.org/10.1016/i.saa.2016.02.044

20. N. Jaryal and H. Kaur, J. Biomater. Sci., 28, 1847 (2017); https://doi.org/10.1080/09205063.2017.1354673.

21. B.S. Bhau, S. Ghosh, S. Puri, B. Borah, D.K. Sarmah and R. Khan, Adv. Mater. Lett., 6, 55 (2014); https://doi.org/10.5185/amlett.2015.5609.

22. L. Christensen, V. Singaravelu, M. Misra and A.K. Mohanty, Adv. Mater. Lett., 2, 429 (2011); https://doi.org/10.5185/amlett.2011.4256.

23. Y. Sha, I. Mathew, Q. Cui, M. Clay, F. Gao, X.J. Zhang and Z. Gu, Chemosphere, 144, 1530 (2016); https://doi.org/10.1016/j.chemosphere.2015.10.040. 